\title{
The Research on Data Center Energy Saving Technology based on DC Power Supply Technology
}

\author{
Cai Zhiyuan ${ }^{1} \&$ Tian Xin $^{1}$ \\ ${ }^{1}$ State Grid Smart Grid Research Institute, Beijing, China
}

KEYWORD: Data center; DC power supply; PUE; energy efficiency

ABSTRACT: Data center energy consumption is increasing with the rapid development of data center in recent years. This paper firstly elaborated data center energy saving technologies from three aspects: the power supply system, the air conditioning system and the IT epuipments, then carried on the energy efficiency comparative analysis of high voltage DC(HVDC) power supply technology and the traditional UPS system power supply technology. We come to the conclusion that the high voltage DC power supply technology obtained the better energy efficiency than the traditional UPS system power supply technology.

\section{Introduction}

With the expansion of IT equipment application scale in the traditional telecommunications, finance, government and other industries, the construction of the data center is growing rapidly, and energy consumption is also soaring. The energy saving becomes more and more important in the background of the energy crisis and the energy saving currently.

\section{A metric used to determine the energy efficiency of data center}

Before the discussion of the data center's energy efficiency, the metric used to measure the energy efficiency of data center should be determined. Generally, EUI (Energy use intensity) was used to determine the enegy efficiency for common buildings. However, there will be some problems if EUI was used to determine the enegy efficiency of data center. Because of the wide variety and different lay out of IT equipments, there will be a big difference in heat dissipation per unit area of IT equipment in different data centers. In this context, the EUI metric lost its significance, a new metric is needed to determine the energy efficiency of data center.

The energy consumption of data centers is mainly distributed in IT equipment, air conditioning system, power supply and distribution system loss, etc. According to the statistical analysis of American National Environmental Protection Bureau, the typical data center's energy consumption structure is shown in Figure 1.

Project Supported by the State Grid Corporation of China (No.SGTJ0000KXJS1400087)

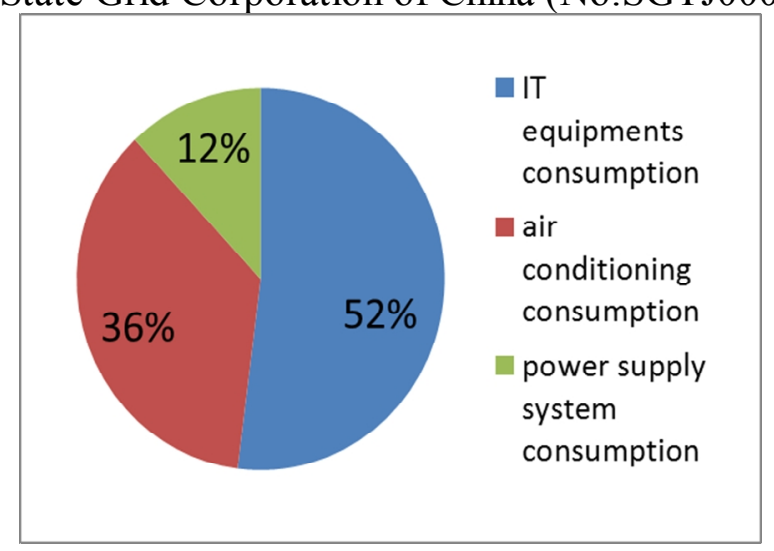

Fig. 1 Data center's energy consumption structure 
In order to standardize the energy efficiency of data center and business computing system, two energy consumption models: PUE (Power Usage Effectiveness) and DCiE (Data Center Infrastructure Efficiency), was proposed by the Grid Green.

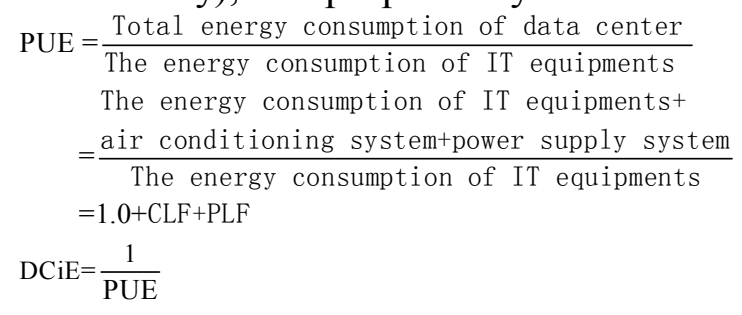

The two energy consumption models can clearly reflect the main power consumption parts of the data center, and provide feasible reference metric for the energy saving design and daily operation of data center.

\section{Overview of energy saving technology of data center}

\section{Energy saving technology of data center's distribution system}

The high-voltage DC power supply system can supply the high voltage DC power to the IT device. The" high-voltage DC power" here is compared to the $48 \mathrm{~V} \mathrm{DC}$ in the traditional telecommunications industry. The electric supply is converted to a high-voltage DC power supply (rectifier process), and then DC power supply directly to the IT power input terminal. It will be converted to $12 \mathrm{~V}, 3.3 \mathrm{~V}$ or $5 \mathrm{~V}$ DC that can be used by the internal logic circuit in the server. Because of the less transformation series, higher supply voltage and less current, the high-voltage DC power supply system has the higher efficiency; because of the structure of the system is simple and the battery pack can directly supply the load in the case of an electric fault, the high-voltage DC power supply system has the higher reliability.

As compared to the conventional UPS power supply system with lower energy consumption and higher reliability, the new data center should give priority to the high voltage DC power supply system.

\section{Energy saving technology of air conditioning system}

The air conditioning system of data center has the important function for the safe and stable operation of data center. Air conditioning energy consumption factor (CLF) is the biggest factor in PUE value, so the energy saving of air conditioning system is the most important aspect of reducing PUE value. So far, the energy saving technology of air-conditioning system mainly includes the following aspects:

(1) Energy saving technology of building envelope

The building envelope should avoid energy loss of the data center room, help to keep a constant temperature. Such aspects should be considered: the room should be located in the shady side of the building, the structure of the room should be column grid, thermal insulation materials should be used in the walls.

(2) Using high energy efficient air-conditioner in data center

There is no energy saving standard in data center air-condition industry so far. Calculating the aircondition load is necessary to preserve the appropriate load margin. Furthermore, to choose the air conditioner with higher value of EER or AEER is to reach the benefits of energy saving from the source.

(3) Cold and heat air flow insulation technique in data center room

Through the appropriate arrangement of wind passage, wind port and layout inside the cabinet, the system ensures that there is no mixture between out wind and return wind. Consequently, this technique could rise the evaporation temperature and increase the energy efficiency for the whole room unit.

(4) Using advanced smart air-conditioner control technique

Air-conditioner control is a multi-input and multi-output lagging system. It has the property of multi-interference, multi-operation modes, temperature relativity and so on. Fuzzy control, neural network control and experts system are also needed besides the traditional PID control. 
(5) Virtualization operation technique of air-condition in data center room

Air-condition virtualization operation technique is based on server virtualization calculation technique. When IT equipment executes virtualized calculation, the heat load of virtualization operation field would increase rapidly; the heat load of dormancy field would decline sharply. It leads to the competitive operation of different air-conditioners in the same data center room because of the original temperature field and air flow distribution will be destructed. Although the server consumption falls, but the air-condition consumption would rise without virtualization operation technique. Thus, to develop the air-condition virtualization operation technique is the certain way to develop the method of energy saving under virtualization operation. Air-condition virtualization operation consists of multiple methods, such as group control energy efficient management, air quantity and cooling capacity adjusting technique.

(6) Virtualization operation technique of air-condition in data center room

High density air-condition's solution is the technique that to make the cooling system closely clings to the server cabinet. It uses high return air temperature, $100 \%$ heat display, energy saving fan and short distance air supply to reduce the operational consumption.

(7) Rack-mounted air-condition design technique

Rack-mounted air-condition design technique is the technique that is able to entirely insulate the air from server cabinet and data center room. It uses the cabinet to refrigerate. This technique maximizes the temperature exchanging efficiency, reduces the distance of supplying air and minimizes the PUE .

(8) Multi low temperature source usage technique

Use the natural medium (cold wind, water and ice outdoor) as the low temperature source, to accomplish the cooling procedure.

\section{Energy saving technology of IT equipments}

(1) Energy saving technology by low power consumption chip

Chip is one of the main heating elements. The chosen of low power consumption chip can improve the energy efficiency of IT equipments. In the premise of the same amount of computation, it can fundamentally reduce the amount of heat of the device. Some studies have pointed out that the energy consumption of CPU equipment $1 \mathrm{~W}$ can reduce, and the other auxiliary power consumption will also be reduced by $1.84 \mathrm{~W}$. The path of energy consumption is shown below.

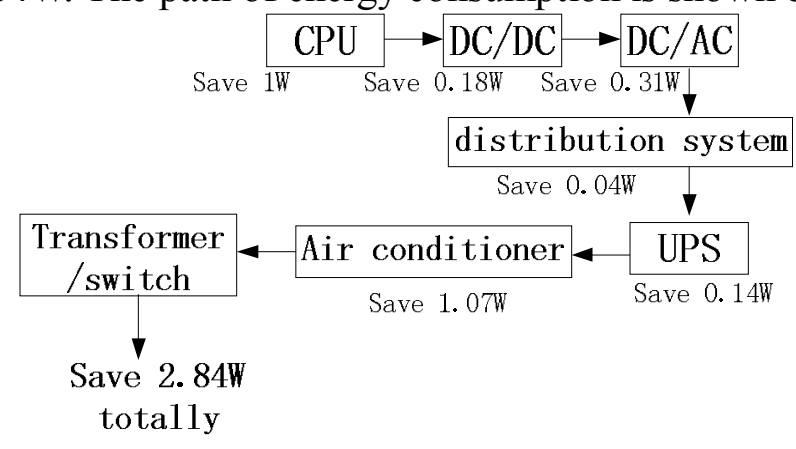

Fig. 2 Diagram of energy consumption path

(2) Energy saving technology of blade type server

The design of blade type server uses the idea of integration. Every piece of blade is actually a system motherboard, similar to a separate server. Its energy consumption is $30 \%$ lower than the traditional server under the same computing power.

(3) Energy saving by virtual computing technology

Multiple logical servers are contained in one single physical server, reduce the amount of physical server operations during the operational trough period, and centralized computing business to a few physical servers. The promotion of virtual computing technology can reduce the number of servers, the core content is to reduce the number of running IT devices as much as possible in the case of completing the amount of calculation. In the practical application, the load rate of the IT equipment must be improved as much as possible to save energy. 


\section{Energy efficiency comparison of different power supply schemes}

\section{Efficiency analysis of UPS system}

According to the measured data of a certain type of UPS system efficiency, the following efficiency table is obtained.

Table 1 Efficiency of UPS system

\begin{tabular}{llllll}
\hline $\begin{array}{l}\text { Load rate } \\
\varepsilon\end{array}$ & $10 \%$ & $25 \%$ & $30 \%$ & $40 \%$ & $50 \%$ \\
\hline $\begin{array}{l}\text { System } \\
\text { efficiency } \\
\omega\end{array}$ & $88.26 \%$ & $91.13 \%$ & $91.57 \%$ & $91.74 \%$ & $92.40 \%$ \\
\hline $\begin{array}{l}\text { Load rate } \\
\varepsilon\end{array}$ & $60 \%$ & $75 \%$ & $80 \%$ & $90 \%$ & $100 \%$ \\
\hline $\begin{array}{l}\text { System } \\
\text { efficiency }\end{array}$ & $92.57 \%$ & $92.79 \%$ & $92.85 \%$ & $92.73 \%$ & $92.50 \%$ \\
\hline
\end{tabular}

According to the efficiency table, the efficiency curve of the UPS system can be drawn as follows:

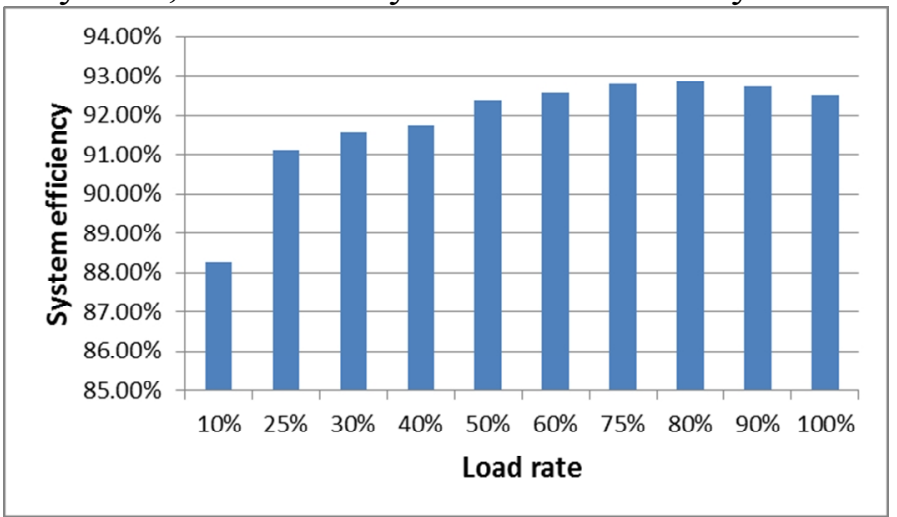

Fig. 3 UPS system efficiency curve

It can be seen that the system efficiency tends to be stable at $93 \%$ when the UPS system load rate is over $50 \%$. The UPS power supply topology diagram is shown in figure 5 , the transmission efficiency of the PDU part in which is $94 \%$.

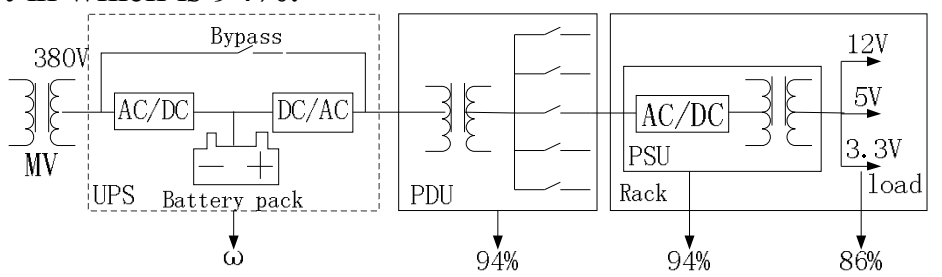

Fig. 4 Topology diagram of UPS system

The energy consumption measure point of the IT device is selected as the PDU output terminal, according to the calculation formula of the energy consumption factor for the power supply system(as shown in formula 2):

$$
\begin{aligned}
\text { PLF } & =\frac{\text { Energy consumption of power supply system }}{\text { Energy consumption of IT devices }} \\
& =\frac{P(1-\omega)}{P \varepsilon 94 \%}=\frac{(1-\omega)}{\varepsilon 94 \%}
\end{aligned}
$$

The PLF table can be obtained as shown in table 2. 
Table 2 PLF calculation of UPS system

\begin{tabular}{llllll}
\hline $\begin{array}{l}\text { Load } \\
\text { rate } \varepsilon\end{array}$ & $10 \%$ & $25 \%$ & $30 \%$ & $40 \%$ & $50 \%$ \\
\hline $\begin{array}{l}\text { System } \\
\text { efficienc } \\
\text { y } \omega\end{array}$ & $88.26 \%$ & $91.13 \%$ & $91.57 \%$ & $91.74 \%$ & $92.40 \%$ \\
\hline $\begin{array}{l}\text { PLF(cos } \\
=0.9)\end{array}$ & 1.388 & 0.419 & 0.332 & 0.244 & 0.180 \\
\hline $\begin{array}{l}\text { Load } \\
\text { rate } \varepsilon\end{array}$ & $60 \%$ & $70 \%$ & $80 \%$ & $90 \%$ & $100 \%$ \\
\hline $\begin{array}{l}\text { System } \\
\text { efficienc } \\
\text { y } \omega\end{array}$ & $92.57 \%$ & $92.79 \%$ & $92.85 \%$ & $92.73 \%$ & $92.50 \%$ \\
\hline $\begin{array}{l}\text { PLF(cos } \\
=0.9)\end{array}$ & 0.146 & 0.122 & 0.106 & 0.095 & 0.089 \\
\hline
\end{tabular}

\section{Efficiency analysis of HVDC supply system}

Efficiency analysis of HVDC $240 \mathrm{~V} / 5.8 \mathrm{~kW}$ single module power supply system

According to the measured data of a model of HVDC $240 \mathrm{~V} / 5.8 \mathrm{~kW}$ single module power supply system efficiency, the following efficiency table can be obtained.

Table 3 Efficiency of HVDC $240 \mathrm{~V} / 5.8 \mathrm{~kW}$ system

\begin{tabular}{llllll}
\hline $\begin{array}{l}\text { Load rate } \\
\varepsilon\end{array}$ & $10 \%$ & $25 \%$ & $30 \%$ & $40 \%$ & $50 \%$ \\
\hline $\begin{array}{l}\text { System } \\
\text { efficiency } \\
\omega\end{array}$ & $84.70 \%$ & $89.90 \%$ & $92.30 \%$ & $93.60 \%$ & $93.90 \%$ \\
\hline $\begin{array}{l}\text { Load rate } \\
\varepsilon\end{array}$ & $60 \%$ & $70 \%$ & $80 \%$ & $90 \%$ & $100 \%$ \\
\hline $\begin{array}{l}\text { System } \\
\text { efficiency } \\
\omega\end{array}$ & $93.90 \%$ & $93.80 \%$ & $93.70 \%$ & $93.70 \%$ & $93.60 \%$ \\
\hline
\end{tabular}

According to the efficiency table, the efficiency curve of the HVDC $240 \mathrm{~V} / 5.8 \mathrm{~kW}$ system can be drawn as follows:

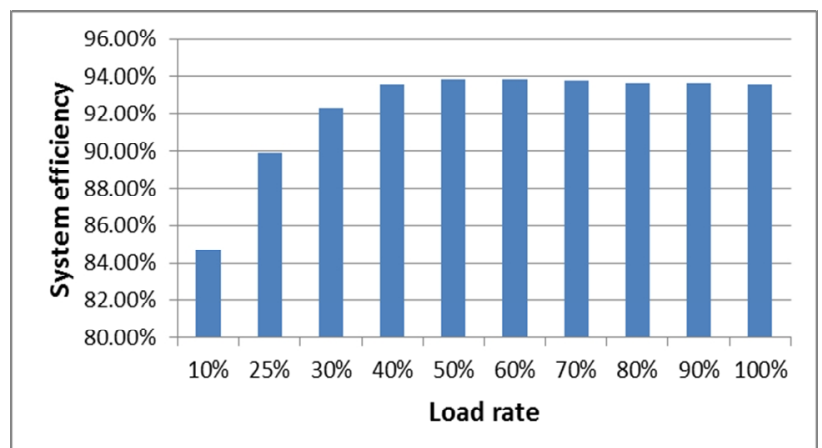

Fig. 5 Efficiency curve of HVDC $240 \mathrm{~V} / 5.8 \mathrm{~kW}$ system

It can be seen that the system efficiency tends to be stable at $94 \%$ when the UPS system load rate is over $50 \%$. The HVDC $240 \mathrm{~V} / 5.8 \mathrm{~kW}$ supply topology diagram is shown in figure 7 , the transmission efficiency of the PDU part in which is $96 \%$. 


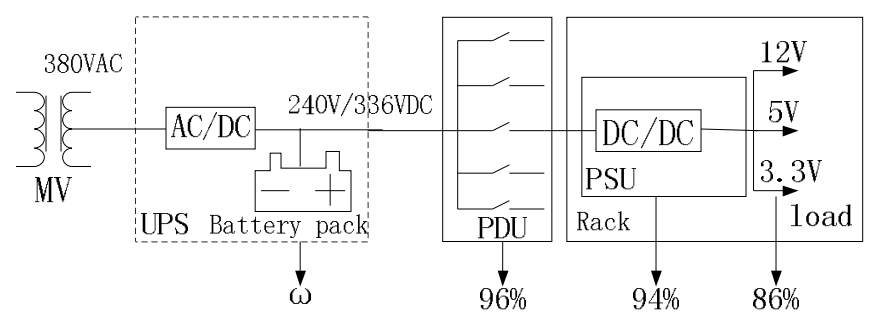

Fig. 6 Topology diagram of HVDC $240 \mathrm{~V} / 5.8 \mathrm{~kW}$ system

The energy consumption measure point of the IT device is selected as the PDU output terminal, according to the calculation formula of the energy consumption factor for the power supply system(as shown in formula 2):

The PLF table can be obtained as shown in table 4.

\begin{tabular}{llllll}
\multicolumn{5}{c}{ Table 4 PLF calculation of HVDC $240 \mathrm{~V} / 5.8 \mathrm{~kW}$ system } \\
\hline $\begin{array}{l}\text { Load } \\
\text { rate } \varepsilon\end{array}$ & $10 \%$ & $20 \%$ & $30 \%$ & $40 \%$ & $50 \%$ \\
\hline $\begin{array}{l}\text { System } \\
\text { efficienc } \\
\mathrm{y} \omega\end{array}$ & $84.70 \%$ & $89.90 \%$ & $92.30 \%$ & $93.60 \%$ & $93.90 \%$ \\
\hline $\begin{array}{l}\text { PLF(cos } \\
=0.9)\end{array}$ & 1.594 & 0.526 & 0.267 & 0.167 & 0.127 \\
\hline $\begin{array}{l}\text { Load } \\
\text { rate } \varepsilon\end{array}$ & $60 \%$ & $70 \%$ & $80 \%$ & $90 \%$ & $100 \%$ \\
\hline $\begin{array}{l}\text { System } \\
\text { efficienc } \\
\text { y } \omega\end{array}$ & $93.90 \%$ & $93.80 \%$ & $93.70 \%$ & $93.70 \%$ & $93.60 \%$ \\
\hline $\begin{array}{l}\text { PLF(cos } \\
=0.9)\end{array}$ & 0.106 & 0.092 & 0.082 & 0.073 & 0.067 \\
\hline
\end{tabular}

\section{Efficiency analysis of HVDC $240 \mathrm{~V} / 15 \mathrm{~kW}$ single module power supply system}

According to the measured data of a model of HVDC $240 \mathrm{~V} / 15 \mathrm{~kW}$ single module power supply system efficiency, the following efficiency table can be obtained.

\begin{tabular}{llllll}
\multicolumn{5}{c}{ Table 5 Efficiency of HVDC 240V/15kW system } \\
\hline $\begin{array}{l}\text { Load rate } \\
\varepsilon\end{array}$ & $10 \%$ & $25 \%$ & $30 \%$ & $40 \%$ & $50 \%$ \\
\hline $\begin{array}{l}\text { System } \\
\text { efficiency } \\
\omega\end{array}$ & $\begin{array}{l}88.26 \\
\%\end{array}$ & $\begin{array}{l}91.13 \\
\%\end{array}$ & $\begin{array}{l}91.57 \\
\%\end{array}$ & $\begin{array}{l}91.74 \\
\%\end{array}$ & $\begin{array}{l}92.40 \\
\%\end{array}$ \\
\hline $\begin{array}{l}\text { Load rate } \\
\varepsilon\end{array}$ & $60 \%$ & $75 \%$ & $80 \%$ & $90 \%$ & $100 \%$ \\
\hline $\begin{array}{l}\text { System } \\
\text { efficiency } \\
\omega\end{array}$ & $\begin{array}{l}92.57 \\
\%\end{array}$ & $\begin{array}{l}92.79 \\
\%\end{array}$ & $\begin{array}{l}92.85 \\
\%\end{array}$ & $\begin{array}{l}92.73 \\
\%\end{array}$ & $\begin{array}{l}92.50 \\
\%\end{array}$ \\
\hline
\end{tabular}

According to the efficiency table, the efficiency curve of the HVDC $240 \mathrm{~V} / 5.8 \mathrm{~kW}$ system can be drawn as follows:

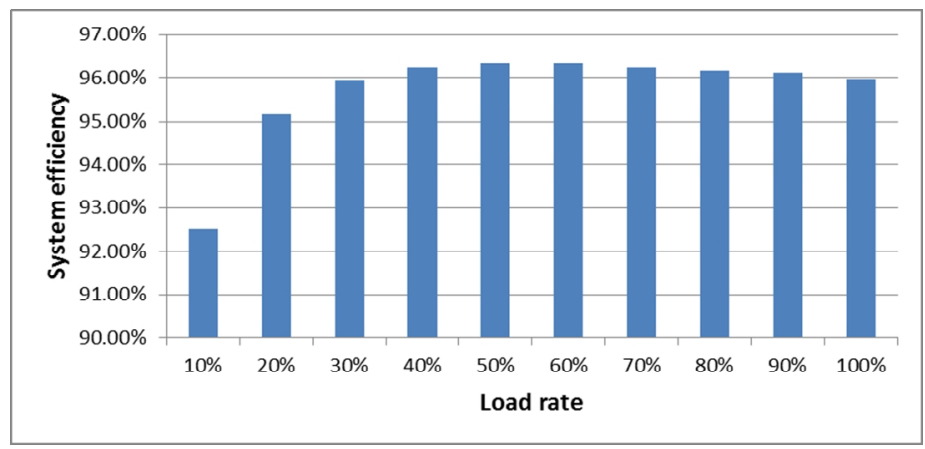

Fig. 7 Efficiency curve of HVDC 240V/15kW system 
It can be seen that the system efficiency tends to be stable at $93 \%$ when the UPS system load rate is over $50 \%$.

According to the calculation formula of the energy consumption factor for the power supply system(as shown in formula 2), the PLF table can be obtained as shown in table 6.

\begin{tabular}{llllll}
\multicolumn{5}{c}{ Table 6 PLF calculation of HVDC $240 \mathrm{~V} / 15 \mathrm{~kW}$ system } \\
\hline $\begin{array}{l}\text { Load } \\
\text { rate } \varepsilon\end{array}$ & $10 \%$ & $25 \%$ & $30 \%$ & $40 \%$ & $50 \%$ \\
\hline $\begin{array}{l}\text { System } \\
\text { efficienc } \\
\text { y } \omega\end{array}$ & $88.26 \%$ & $91.13 \%$ & $91.57 \%$ & $91.74 \%$ & $92.40 \%$ \\
\hline $\begin{array}{l}\text { PLF(cos } \\
=0.9)\end{array}$ & 1.388 & 0.419 & 0.332 & 0.244 & 0.180 \\
\hline $\begin{array}{l}\text { Load } \\
\text { rate } \varepsilon\end{array}$ & $60 \%$ & $70 \%$ & $80 \%$ & $90 \%$ & $100 \%$ \\
\hline $\begin{array}{l}\text { System } \\
\text { efficienc }\end{array}$ & $92.57 \%$ & $92.79 \%$ & $92.85 \%$ & $92.73 \%$ & $92.50 \%$ \\
y $\omega$ & 0.122 & 0.106 & 0.095 & 0.089 \\
\hline $\begin{array}{l}\text { PLF(cos } \\
=0.9)\end{array}$ & 0.146 & 0.105 & \\
\hline
\end{tabular}

Efficiency analysis of HVDC 336V/15kW single module power supply system

According to the measured data of a model of HVDC $336 \mathrm{~V} / 15 \mathrm{~kW}$ single module power supply system efficiency, the following efficiency table can be obtained.

\begin{tabular}{llllll}
\multicolumn{5}{c}{ Table 7 Efficiency of HVDC 336V/15kW system } \\
\hline $\begin{array}{l}\text { Load } \\
\text { rate } \varepsilon\end{array}$ & $10 \%$ & $25 \%$ & $30 \%$ & $40 \%$ & $50 \%$ \\
\hline $\begin{array}{l}\text { System } \\
\text { efficienc } \\
\text { y }\end{array}$ & $93.17 \%$ & $96.20 \%$ & $96.65 \%$ & $97.25 \%$ & $97.30 \%$ \\
\hline $\begin{array}{l}\text { Load } \\
\text { rate } \varepsilon\end{array}$ & $60 \%$ & $70 \%$ & $80 \%$ & $90 \%$ & $100 \%$ \\
\hline $\begin{array}{l}\text { System } \\
\text { efficienc } \\
\text { y } \omega\end{array}$ & $97.39 \%$ & $97.36 \%$ & $97.33 \%$ & $97.22 \%$ & $97.20 \%$ \\
\hline
\end{tabular}

According to the efficiency table, the efficiency curve of the HVDC $336 \mathrm{~V} / 5.8 \mathrm{~kW}$ system can be drawn as follows:

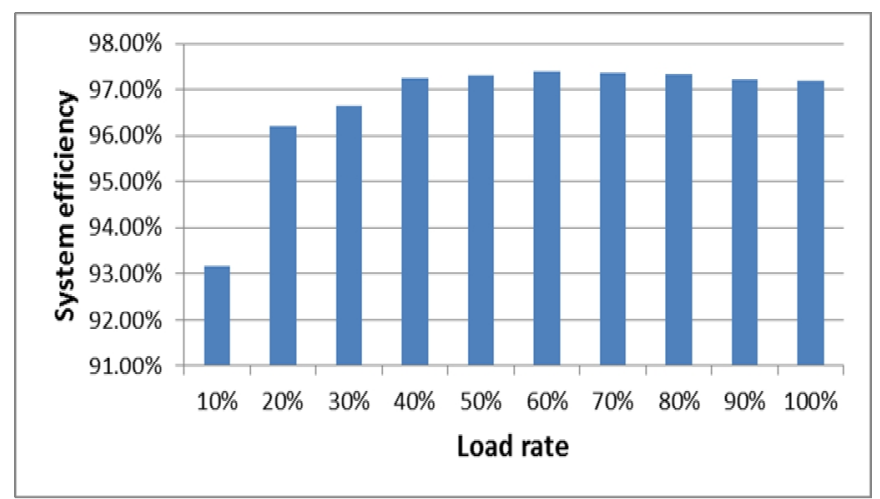

Fig. 8 Efficiency curve of HVDC $336 \mathrm{~V} / 15 \mathrm{~kW}$ system

It can be seen that the system efficiency tends to be stable at $93 \%$ when the UPS system load rate is over $50 \%$.

According to the calculation formula of the energy consumption factor for the power supply system(as shown in formula 2), the PLF table can be obtained as shown in table 8 . 
Table 8 PLF calculation of HVDC $336 \mathrm{~V} / 15 \mathrm{~kW}$ system

\begin{tabular}{llllll}
\hline $\begin{array}{l}\text { Load } \\
\text { rate } \varepsilon\end{array}$ & $10 \%$ & $25 \%$ & $30 \%$ & $40 \%$ & $50 \%$ \\
\hline $\begin{array}{l}\text { System } \\
\text { efficienc } \\
\text { y } \omega\end{array}$ & $93.17 \%$ & $96.20 \%$ & $96.65 \%$ & $97.25 \%$ & $97.30 \%$ \\
\hline $\begin{array}{l}\text { PLF(cos } \\
=0.9)\end{array}$ & 0.711 & 0.198 & 0.116 & 0.072 & 0.056 \\
\hline $\begin{array}{l}\text { Load } \\
\text { rate } \varepsilon\end{array}$ & $60 \%$ & $70 \%$ & $80 \%$ & $90 \%$ & $100 \%$ \\
\hline $\begin{array}{l}\text { System } \\
\text { efficienc }\end{array}$ & $97.39 \%$ & $97.36 \%$ & $97.33 \%$ & $97.22 \%$ & $97.20 \%$ \\
\begin{tabular}{l} 
y $\omega$ \\
\hline $\begin{array}{l}\text { PLF(cos } \\
=0.9)\end{array}$
\end{tabular} & 0.045 & 0.039 & 0.035 & 0.032 & 0.029 \\
\hline
\end{tabular}

\section{Comparison of energy saving effect of different power supply systems}

Summarize the PLF values of the UPS system and different HVDC systems, the PLF values list can be obtained as follows.

Table 9 The PLF values of different power supply systems

\begin{tabular}{lccccccc}
\hline Load rate $\varepsilon$ & $40 \%$ & $50 \%$ & $60 \%$ & $70 \%$ & $80 \%$ & $90 \%$ & $100 \%$ \\
\hline $\begin{array}{l}\text { PLF_ } \\
\text { UPS }\end{array}$ & 0.244 & 0.180 & 0.146 & 0.122 & 0.106 & 0.095 & 0.089 \\
\hline $\begin{array}{l}\text { PLF_- } \\
240-5.8\end{array}$ & 0.167 & 0.127 & 0.106 & 0.092 & 0.082 & 0.073 & 0.067 \\
\hline $\begin{array}{l}\text { PLF_ } \\
240-15\end{array}$ & 0.098 & 0.076 & 0.064 & 0.056 & 0.050 & 0.045 & 0.042 \\
\hline $\begin{array}{l}\text { PLF_- } \\
336-15\end{array}$ & 0.072 & 0.056 & 0.045 & 0.039 & 0.035 & 0.032 & 0.029
\end{tabular}

Then, the Comparison chart as figure 9 can be drawn according the PLF values list of different power supply systems.

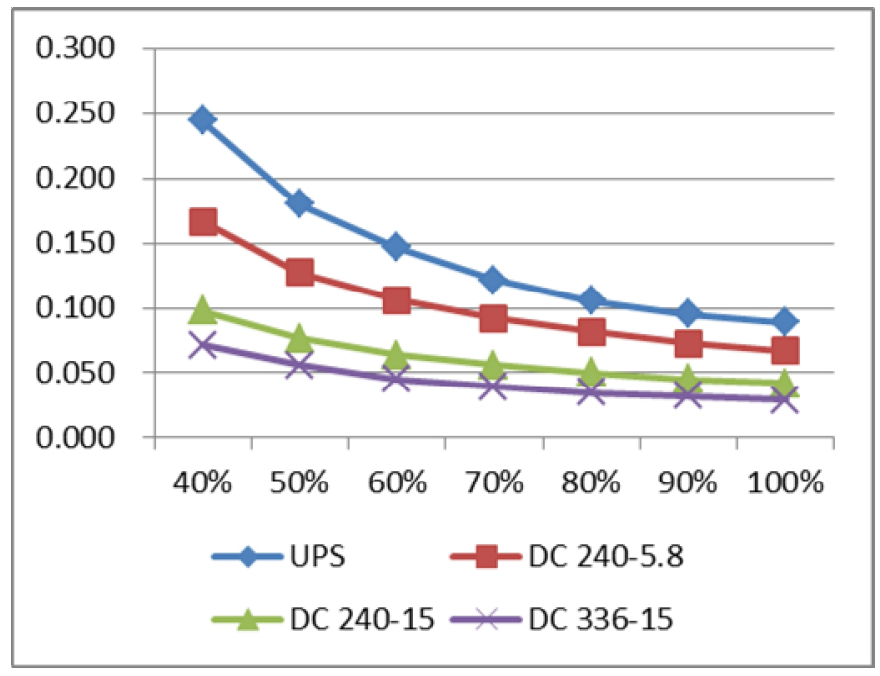

Fig. 9 The Comparison chart of different power supply systems

The different HVDC power supply systems can reduce the PLF values, thereby reducing the PUE values in different degree compared with the traditional UPS power supply system, improve the efficiency of data center in different degree. We can conclude that the PLF value thereby the PUE value can be reduced by improving the voltage and power of the HVDC system within reasonable limits through comparing the three of $336 \mathrm{~V} / 15 \mathrm{~kW}, 240 \mathrm{~V} / 15 \mathrm{~kW}$ and $240 \mathrm{~V} / 5.8 \mathrm{~kW}$ power supply systems. 


\section{Conclusions and Outlook}

This paper summarizes the main energy saving technologies currently that can improve the energy efficiency of data center, including the energy saving technology of data center's distribution system, the energy saving technology of air conditioning system, the energy saving technology of IT equipments for three aspects. Then a comparative analysis of traditional UPS supply system and three kind of HVDC supply systems was made, It is concluded that the energy efficiency of data center could be improved by different HVDC supply systems in different degree, and improving the voltage and power of the HVDC system within reasonable limits could further improve the energy efficiency of data cener.

But, the energy consumption of power supply system is not high compared with IT equipment and air conditioning system. The energy saving technology of IT equipment and air conditioning system should be studied to improve the energy efficiency of data center greatly in the future.

\section{References}

[1] Mitchell-Jackson, Jennifer, Jonathan Koomey, et al. Data Center Power Requirements: Measurements From Silicon Valley [J]. Energy, 2003, 28(8): 255- 269

[2] R.R.Schmidt,E.E.Cruz M.K.Iyengar.Challenges of data center thermal management[J] IBM Journal of Research and Development. 2007.25(4):15-17

[3] Green grid metrics: Describing Datacenter Power Efficiency. Green Grid[EB/OL].http://www. thegreengrid. $\quad$ org/gg_content/TGG_Data_Center_ Power_E fficiency_Metrics_PUE_and_DCiE.pdf, 2011-02-13

[4] Christian Belady.How to Minimize Data Center Utility Bills [EB/OL]https://www.line56.com/articles/default.asp?ArticleID=7881,2006-01-15

[5] Patterson, Costello, Grimm, et al. A Comparison of High-density and Low-density Spaces[R]. Santafe: THERMES, 2007

[6] William Tschudi, Tengfang Xu, Dale Sartor, et al. Energy efficient data centers. Final Draft Rep[R]. Berkeley: Lawrence Berkeley National Laboratory, 2003

[7] Steve Greenberg, Evan Mills, Bill Tschudi, et al. Best Practices for Data Centers: Results from Benchmarking 22 Data Centers[C]. ACEEE. Proceedings of the 2006 ACEEE Summer Study on Energy Efficiency in Buildings. Washington, DC, 2006.

[8] S. Sahni and T. Gonzalez, "P-complete approximation problems," Journal of the Association of Computing Machinery, vol. 23, pp. 555-565, 1976.

[9] M. R. Garey and D. S. Johnson, Computers and Intractability: A Guide to the Theory of NPCompleteness. W.H.Freeman, 1979

[10]H. Saran and V. V. Vazirani, "Finding k cuts within twice the optimal," SIAM J. Comput., vol. 24, no. 1, pp. 101-108, 1995

[11]Zhong Jinghua, Zhu Liwei, Cao broadcast, and other planning and design of a new generation green data center [M] Beijing: Electronic Industry Press, 2010

[12]Bo Yide Green Building Technology Guide [M]. Beijing. China Building Industry Press. 2008.415

[13] Wang Qiying, He Chunhua. UPS power supply system integrated solutions / Power Series [M]. Beijing Electronic Industry Press. 2007.302 China Electronics Engineering Design Institute GB50174-2008 electronic information system room design specifications [S]. Beijing: China Planning Press, 2009

[14]Zhang Tao, Liu Xiaohua, zhaokang, and other temperature and humidity independent control air conditioning system application performance analysis [J] Building Science, 2010, 26 (10): 146150 